Boise State University ScholarWorks

Communication Faculty Publications and

Presentations

Department of Communication

$10-1-2008$

Secular Spirituality/Mundane Media: One Newspaper's In-Depth Coverage of Buddhism

Rick Clifton Moore

Boise State University 


\title{
Secular Spirituality/Mundane Media: One Newspaper's In-depth Coverage of Buddhism
}

\author{
Rick Clifton Moore, Ph.D. \\ Associate Professor \\ Department of Communication \\ Boise State University \\ Boise, ID 83725-1920 \\ rmoore@boisestate.edu \\ Phone: (208) 426-3562 \\ Fax: (208) 426-1069
}

\begin{abstract}
:
This paper addresses Mark Silk's theory of "unsecular media" through a case study of a visit the Dalai Lama made to the United States. Silk contends the themes (what he calls "topoi") media use to cover religion are derived from Western faiths. Thus, according to Silk, when Western religious principles are used to write about Western religious practices, those practices are generally evaluated positively. In the analysis that follows I examine the extent to which Silk's topoi were used to report about Buddhism, an obviously "Eastern" religion. The basic findings suggest that Silk's topoi were readily applied in the stories analyzed here, but more importantly that the tone of coverage this produces was quite positive. These findings raise a very important question. Are the topoi that Silk has delineated the direct product of Western religion, or are they more accurately the reflection of general moral principles that are accepted by journalists and a large part of their audience?
\end{abstract}

\section{Introduction}

Mark Silk's Unsecular Media is arguably one of the most important books written about news coverage of religion. One highly respected media scholar said that it "may be the most significant book on this subject to date" (Stout, 1997, p. 128). Another reviewer stated that, "Silk's book should be essential reading for researchers on religion and the mass media because the central argument is so stimulating and provocative" (Beckford, 1996, p. 89-90).

Challenging a widely held belief that the news media are anti-religious, Silk used a topical approachanalyzing recurring themes in news coverage - to suggest that the opposite is the case. In a nutshell, his argument is that those who work in the news media use (perhaps unwittingly) foundational beliefs from religion when they write about matters of faith. When they do so, they privilege religious ways of viewing the world over secular ways. Two respected scholars of media and religion summed up Silk's argument succinctly, saying that "values underlying newspaper coverage of religion ultimately turn out to be the same as values espoused by dominant religious institutions" (Stout and Buddnebaum, 2002, p. 10).

Perhaps because the abstract theory Silk proposed is so new and provocative, many of those who encountered it failed to note an obvious limitation. Though the book's subtitle is Making News of Religion in America, it is noticeably lacking in analysis of news coverage of faiths that are not Abrahamic. The bulk of the discussion is limited to Judaism, Christianity, Islam, and Mormonism. Almost absent from the book 
is analysis of Eastern ${ }^{1}$ religions such as Buddhism and Hinduism. ${ }^{2}$ Admittedly, as Unsecular Media broke new ground in the study of religion and news, we cannot expect it to venture into all aspects thereof. To put this in positive terms, Silk can be thanked for creating a need to delve further into news coverage of religious faiths that are not Abrahamic.

Another area in which Silk's trenchant conceptual model creates need is in the area of specificity. Being so broadly focused on the whole of American journalism and religion, the author is never able to give a thorough analysis of any part thereof. Hence, much of his work is anecdotal, rarely giving clear indication of the boundaries of analysis. Perhaps with this in mind, James Beckford, the same reviewer who called the book "provocative," said, "It illustrates but it does not test; it summarizes, but it does not compare" (Beckford, 1996, p. 90).

Silk's book is thus stimulating and provocative, but only the beginning of a project to paint a clearer picture of media and religion. I would like to suggest that much study is to be done before any of us can say with certainty that the media are largely "unsecular." Great detail must be added to what Silk has already told us. If the detail seems to support his broad claims, we will say with much more confidence that the news media—on the whole—exhibit a "proreligious posture" (Silk, 1998, p. 148). If the detail turns out to make the picture he has painted more blurry, or, if the detail begins to reveal a very different picture, we should devote our attention to a theory other than Silk's even if his is stimulating and provocative.

What I provide here is a study of news about a non-Western religion within a very narrow context. In an attempt provide analysis that is more systematic than what has already been shared in Unsecular Media, I examine a very specific set of data. And, in an attempt to ask questions about how coverage of nonWestern religious traditions fits into Silk's theory, the news stories studied here all relate to Buddhism. Within this framework a set of findings arise that are partially supportive of Silk's claims about the media and religion. The material in the following pages does seem to indicate that reporters are compelled to utilize restrictive themes when writing about religion. However, the extent to which those themes arise from, and support, Western religion is much more open to question.

\section{Topoi that Defy Secularity—Do They Apply to Other Faiths?}

As noted above, the gist of Silk's thesis is that news reporters rely heavily on "topoi" (the plural form of the Greek word "topos") to report news of religion and that this props up a religious worldview. To understand this process in more detail, some discussion of the nature of topoi and Silk's analysis of them will be helpful.

Topoi are prevalent "cultural preconceptions" or "commonplaces" that reporters use to tell stories (Silk, 1998, p. 50). And in Silk's view, when the story is about religion, the topoi that are recruited are topoi that reflect dominant religious tradition and thought. His claim is that when writing about matters of faith, journalists operate "with ideas of what religion is and is not, of what it ought and ought not to be-with topoi-that derive, to varying degrees, from religious sources" (p. 55). To help us see the religious nature of topoi that are used in reporting about faith, Silk provides specific examples, briefly notes their theological origins, and demonstrates some of their common applications. He devotes a chapter to each of seven topoi: good works, tolerance, hypocrisy, false prophecy, inclusion, supernatural belief, and declension. At the beginning of each of these chapters, he provides a verse from Hebrew or Christian scripture. For example, to note the religious origins of the concept of "good works," he cites Isaiah 58:6, a verse calling its readers to care for the poor (Silk, 1998, p. 57). Within the text of each chapter, he demonstrates some of the ways news media have relied on this prescription (or proscription) to frame a particular story about faith. Returning to the example of the chapter on "good works," we see that Silk analyses a story from the Atlanta Journal-Constitution that discussed President Jimmy Carter's challenge for religious peoples to be more involved in their communities (p. 58).

Silk presents all of this evidence with full awareness that many perceive the media to be anti-religious. He acknowledges that certain Christian groups are especially prone to hold a view that the media are agents of secularism. ${ }^{3}$ In spite of these common perceptions that the media are antagonistic to religion, though, Silk proposes that the media are subtly corroborative. The stories that journalists write are highly dependent on 
and highly supportive of a theological worldview, he says. This is not necessarily because the reporters hold strongly to this theological worldview themselves, but because the culture they live in is so richly infused with it. In brief form he states, "secular-religious tension is far less important than Western religious culture per se in explaining how American news media cover religion" (Silk, 1997, p. 54). Reporters who draw on cultural resources cannot help but write using religious elements, perhaps even doing so unconsciously.

Silk thus claims that those who hold a theological world view-the vast majority of citizens in the United States-should find such a media environment very comforting. Or, at the very least, they should find it inoffensive (Silk, 1998, p. 141). After all, according to his argument, their theological foundations are being used as the measuring stick to determine the validity of their religious institutions. One would presume that this system works to the benefit of the prevailing religious institutions. To re-trace one example from the book, Silk claims the topos of "tolerance" leads reporters to write about religion in a way that benefits the Christian church. Silk supports this claim by citing a verse from "Judeo-Christian" scripture (Matthew 5:43-44) that suggests the source of this topos, then by defining the topos as it is envisioned by our broader culture, and finally by providing numerous anecdotes that demonstrate how it has been played out in the media. In brief, then, Silk's thesis is that when tools for evaluating religion are gathered from a specific religion and then applied to that religion, the religion is going to (naturally) fare quite well. To provide a metaphor from sports, if a team is permitted to write the rulebook under which they compete, they should presumably not be too worried about the officiating crew for their games. As long as the team knows that the officiating crew is going to stick to that rulebook, what is there to fear?

But, this raises significant issues related to a key limitation noted earlier. If we are interested in understanding the coverage of religion in America, must we not ask how the topoi Silk describes are applied to religions that have no roots in Judaism? To put this in other terms, what of religions that have no connection to the teachings of Moses, Jesus Christ, Mohamed, or Joseph Smith? ${ }^{4}$ The basic research questions of the paper that follows arise from these broader interrogations and in their simplest form are rather direct. Are the topoi that Silk claims have developed from the Judeo-Christian tradition evident in reporting about religious traditions with no direct historical link to that faith tradition? And, if those topoi are applied to these alternative faiths, do these faiths fare well (as Silk claims that Christianity does)?

These questions are important for two reasons. First, they suggest a key area where the implications of Silk's ideas about media and religion need to be explored. Second, they allude to broader issues of media portrayal of the diverse religions that exist in $21^{\text {st }}$ century America. The first of these is clearly important as Silk's conception of media and religion is an important one in the academy. ${ }^{5}$ This has already been discussed. The second is important because it relates to more abstract research areas such as the relationship between media diversity and secularity that can be looked at from perspectives very different from what Silk has proposed.

\section{Research on Media and Religious Diversity}

In a recent book, Lynn Shofield Clark suggested "increased attention is being given to the representation of non-Christian, non-Western groups in the news media" (Shofield Clark, 2002, p. 17). Most who read her words were probably pleased by them, as increased breadth in the study of religion and media could be seen as a sign of maturity in the sub-discipline, a sub-discipline itself recognized as being "seriously understudied" (Stout and Buddenbaum, 2002, p. 5). Unfortunately, what Clark provided as evidence of "increased attention" was only two conference papers and one book. The book was published in 1981.

Some explanation for the small number of studies that investigate media portrayal of minority religions is found in the media themselves. Portrayal of religion in the mainstream media has tended to be scant. Given this, minority faiths, as a small part of an already scant sample, become almost imperceptible. In her groundbreaking study of newspaper coverage of religions in the early 1980s, Buddenbaum coded for religions that are "not associated with the Judeo-Christian tradition," but found little evidence of such, noting only one story, a piece about the International Society for Krishna Consciousness (Buddenbaum, 1986, p. 604). Unless such religions were the source of problems (Islam, for example, has consistently been 
covered in relation to its conflicts with Israel) they tended to not exist in any significant amount in the media. Sharing what he sees as a specific manifestation of this tendency, Harvey Cox has suggested that Eastern religions received very little press coverage until they began attracting the children of well-to-do whites (Cox, 1978, p. 124-125).

But "lack of coverage" as an excuse for not understanding portrayal of minority faiths in the media can only go so far. Even Silk makes numerous anecdotal references to news coverage of religions other than Judaism and Christianity. And, one early study did use a more empirical, systematic approach to this subject, but barely scratched the surface in this area (van Driedl and Richardson, 1988). More recently, Sean McCloud's in-depth study of "fringe" religions gives some indication of coverage, though in many ways his fascinating book focuses on why coverage is the way it is more than it focuses on the nature of coverage itself (McCloud, 2004). Moreover, his work tends to focus on "new religious movements" and his data set includes news coverage from fifty years ago.

Moving beyond McCloud, what is known about news coverage of historic world religions (as opposed to "NRMs")? And what can we say about how they are covered in the late $20^{\text {th }}$ and early $21^{\text {st }}$ century? More specifically, how might modern news organizations cover a historically rich religion such as Buddhism? ${ }^{6}$ Melissa Wall did attempt to get some answers to these questions in the mid 1990s. She investigated news coverage of a woman in Washington State who claimed her son was the reincarnation of a highly revered Tibetan lama. Wall examined the coverage by looking at how the story was framed. In regard to the religious dimensions, she suggested that Buddhism was shown to be "downright strange or even comical" (Wall, 1999, p. 14). Even so, she did recommend that further research on media coverage of Buddhism is warranted, "especially with the increasingly high profile the religion has in Western culture" (p. 14).

One scholar who takes a broad perspective that is similar to Silk's, has made speculations about news coverage of Buddhism that strongly contradict Wall's findings. Like Silk, Doug Underwood is interested in the overall religious dimensions of the American press. However, he studies those dimensions not through analysis of media content, but through analysis of media producers. Partly on the basis of his understanding of such media practitioners, he has suggested that Buddhism receives mostly positive coverage in the press. Specifically, Underwood (2002) states:

There are other religions, though, that are portrayed much more favorably by the American media, particularly if they seem open, tolerant, and passive and do not threaten the political or economic order. Buddhism, for example, gets generally good press in the United States, partly because Buddhist leaders (with the exception of the Dalai Lama) are not usually involved in national politics in Asia or other parts of the world. Buddhism is a religion that stresses individual detachment, the search for inner peace, and values of cooperation and tranquility, and, on only rare occasions, has it been the religious inspiration of those trying to change the political order or in

any way threaten American global interests. (p. 268).

Though for many of us Underwood's claim would seem completely reasonable, and we might have personal observations of news coverage that support it, little research has been done in this area. Underwood himself notes that the evidence he has gathered in this area is not substantial. ${ }^{7}$ And, Wall's study seems to contradict his claims (unless one can show that the "little lama" story is one of Underwood's exceptions, that the boy or his mother were trying to "change the political order"). In sum, more investigation in this area is merited. 


\section{The 2005 Dalai Lama Visit as a Case Study}

Given Wall's assessment that news coverage of Buddhism is worthy of continued investigation and Underwood's speculation that it is typically positive, here I provide an in-depth analysis of one paper's treatment of that religious tradition. And, aligning this research with concerns raised about Silk's theory of unsecular media, I attempt to engage that study in a way that has respect for his framework. In short, the following analysis attempts to increase our understanding of the way the American press portrays Buddhism, while continuing to grapple with issues that Mark Silk raised in regards to the overall religiosity of the media as institutions.

The "case" around which this study revolves is the September, 2005 U.S. visit of the Dalai Lama, spiritual leader of Tibetan Buddhism. During his visit, the Dalai Lama spent a week in the state of Idaho. This allowed The Idaho Statesman, the state's largest newspaper, to give ample coverage to the person and his religious tradition. During the week of September $11^{\text {th }}$ The Statesman (a corporate-controlled daily with a circulation of just over 65,000 copies $^{8}$ ) devoted much attention to the Dalai Lama and to Buddhism in general. It published a total of fifteen articles about the man and his message. ${ }^{9}$

The methodological implications of this are worth discussing here. Stout and Buddenbaum refer to what Silk does in his book as moral literary analysis (Stout and Buddenbaum, 2002, p. 10). Such analysis requires the researcher to read the text carefully and look for recurring themes. As noted earlier, one drawback to Silk's work is that he does this with numerous media (newspapers, magazines, even film) over a large period of time (from the colonial period to the present). All counted, he covers over 200 years of history and a variety of media in a scant 181 pages.

In studying the Dalai Lama's representation in The Idaho Statesman, a similar moral literary analysis can be performed, but with a concrete set of newspaper articles from a specific period of time. Admittedly, there is a limit to this approach, but it is minor. One might argue that the coverage in the Statesman was in some way idiosyncratic because of the nature of the newspaper. Yet this seems unlikely, as publications of this size exist in a world where journalists are formally educated and media are corporately controlled businesses. Moreover, any limitations here can be overcome in continuing research. On the other hand, there are significant advantages to studying this specific, limited case. Focusing on a week of coverage from a single paper allows enough text to give us ample "data," but not so much that the analysis becomes superficial. The amount of text available here provided for plenty of material (as will be seen in the following pages) in which to seek the various topoi Silk presents. And, each story could be carefully read and considered. Moreover, readers of this research are able to fully investigate the writing examined, fifteen stories from The Idaho Statesman that ran in September of 2005. It is a clearly defined body of text. Dates, headlines, and page numbers for all stories are provided in Table 1. Following Silk's lead, I simply read these stories numerous time, paying specific attention to any elements that would fit the topoi which he has developed. A discussion of the use of each follows. 


\begin{tabular}{|c|c|c|}
\hline \multicolumn{3}{|c|}{ TABLE 1} \\
\hline \multicolumn{3}{|c|}{ Date, Headline, Location of Idaho Statesman Stories } \\
\hline Date & Headline & Page\# \\
\hline 11-Sep-06 & Dalai Lama's visit shines a light on Idaho Buddhists & Main 1 \\
\hline \multirow[t]{7}{*}{ 11-Sep-06 } & Four local Buddhists share their experiences & Main 4 \\
\hline & "It just clicked in my mind and heart." & Main 4 \\
\hline & "I didn't know that all along I was a Buddhist." & Main 4 \\
\hline & "It rooted me into facing my mind." & Main 4 \\
\hline & "I'm not as overcome by what happens. I don't get as angry." & Main 4 \\
\hline & What is Buddhism? & Main 5 \\
\hline & Buddhism in the West: Dalai Lama continues to bring messages to the U.S. & Main 5 \\
\hline \multirow[t]{3}{*}{ 12-Sep-06 } & Dalai Lama calls for hope, compassion & Main 1 \\
\hline & Dalai Lama visits Idaho. "His message of peace and kindness speaks to me." & Main 4 \\
\hline & Dalai Lama visits Idaho. Dalai Lama reminds Americans of their rights. & Main 5 \\
\hline \multirow[t]{2}{*}{ 13-Sep-06 } & $\begin{array}{l}\text { "The century of compassion is your responsibility." The Dalai Lama, speaking } \\
\text { to children in Hailey }\end{array}$ & Main 1 \\
\hline & His Holiness blesses a family coping with tragedy & Main 4 \\
\hline \multirow[t]{2}{*}{ 14-Sep-06 } & The Dalai Lama blesses Idaho garden prayer wheel & Main 1 \\
\hline & Students see peace message missed by adults & Main 1 \\
\hline \multirow[t]{2}{*}{ 15-Sep-06 } & Dalai Lama asks Idaho religious leaders to seek commonalities & Main 4 \\
\hline & Thoughts about the interfaith meeting with the Dalai Lama & Main 4 \\
\hline
\end{tabular}

\section{Silk's Unsecular Topoi and the Dalai Lama Visit}

Silk (1998) refers to the topoi he provides in his book as "boundary stones that mark out the territory that religion occupies in American journalism" (p. 55). Presumably, the boundaries are generalized, not succinct, and some stories do not fit within them. But, equally presumably, any time we encounter a large body of news about religion, we will find some of the news to be framed within the themes he has noted. Those themes are good works, tolerance, hypocrisy, false prophecy, inclusion, supernatural belief, and declension.

\section{Good Works}

Silk (1998, p. 55) argues that American news media fully accept that religion is a good thing. What are the reasons or this presupposition? A chief one is that many of the activities of religious bodies benefit the members of those bodies as well as the community at large. Silk refers to this as "good works." Moreover, these works reflect a "moral stance" (one shared by the media, according to Silk) that "is derived not from a secular worldview but from the Western religious tradition" (Silk, 1998, p. 59).

Surprisingly, though, "good works" was one of the most common topoi called upon to help readers understand Buddhism as it was embodied by the 2005 visit of the Dalai Lama. The surprising element here is, of course, that Buddhism is an ostensibly Eastern religious tradition. If the "moral stance" of "good works" is derived from the Western religious tradition-as Silk implies-it somehow gets intertwined in media coverage of Eastern ones as well.

Perhaps some of this can be explained by the fact that the Tibetan religious leader timed his visit to mark the commemoration of September 11. From the first announcements of the sojourn, the theme was "compassion." And in a world where many have become detached and cynical (thinking that good works have little impact on their environment) the initial story that appeared the day after the Lama's first speech lead with the quotation, "Don't give up on the world." The headline was "Dalai Lama calls for hope, compassion." 
This theme and related good works dimensions were elicited in other stories. In the edition of the paper that reported about the first speech, another story focused on audience reaction to the message (September 12, "His message of peace..."). This was also largely related to benevolence. Another story, one that recapped the Dalai Lama's special message to children (a speech that occurred a day later) was framed around the idea of youthfulness, but that idea was mostly a means of suggesting that the burden of good works is being shifted from the aged population to youths. In the Dalai Lama's own words delivered to the young audience, "The century of compassion is your responsibility." On the day of this coverage, the paper's commentary writer provided another account. In his direct assessment of the message, he referred to it not only as a call for compassion, but also a call for peace, a definite "moral stance," as Silk would call it. It was a moral stance with which the reporters, and especially the commentary writer-as will be shown later-appeared to heartily agree.

\section{Tolerance}

Silk's second topos is that of tolerance, or as described in the chapter he devotes to the topos, the media's exposure and rejection of intolerance. When the chapter is examined critically, we see that its author actually has two issues to deal with. One of those is intolerant religion. The other is intolerance of religion. According to Silk, neither is acceptable to the press.

He spends little time discussing the first of these. In fact, very few words in the chapter on "Tolerance" are devoted to intolerant religious institutions. But the theme is explored in earlier chapters. Silk proclaims that American media support a "civil religion" that operates within certain constraints, that is, to not overtly attack other religions. When groups disregard these constraints, Silk $(1998$, p. 9) says, they are summarily criticized by other religious bodies, and the media join in the criticism.

Nowhere in coverage of the Dalai Lama's visit was there any indication that Buddhism was an "uncivil" or "intolerant" religion in this sense. There was no hint that anything the Lama said was considered to be an attack on other religious bodies. In fact, a journalist's report of one of his speeches said he listed "religious intolerance" as one of the "confounding problems" of our times and that he specifically called for "tolerance in the face of fundamentalists and fanatics from all faiths" (September 12, "Dalai Lama calls for hope..."). Buddhism, then, as represented by the Dalai Lama, is a highly tolerant faith. And, in such a liveand-let-live environment, nothing in the articles written indicated than any other religious body acted intolerantly toward Buddhism. ${ }^{10}$

The second aspect of tolerance Silk discusses is more directly related to the freedom of religious persons to engage in civic action than it is related to "attacks." The example the theorist gives most attention to is the willingness of the press to defend Roman Catholic politicians (specifically Alf Smith and John F. Kennedy) from those who felt these politicians were not worthy to serve because of their religious beliefs. In some ways, the topos is the recognition of a right, "the right of the religiously committed to engage in politics" (Silk, 1999, p. 71). Themes of tolerance thus are most apparent when the media perceive an air of "intolerance" within the community, that is, when any citizen argues

that religious people cannot be politically active. Looked at another way, the topos of tolerance is somewhat reactionary. It is not called up unless it is needed in reaction to earlier messages. Presumably, those earlier messages-messages of intolerance--must be available in the media themselves for the reaction to occur.

No such intolerant messages occurred in the coverage of the Dalai Lama's visit. The paper did make mention of the religious leader's political activities (broadly defined). They alluded to his disagreements with China over its invasion of his homeland. They also alluded to his winning of the Nobel Peace Prize. But there was no suggestion that anyone thought these acts overtly political or that the Buddhist monk should not be so involved. The theme of tolerance thus had no opportunity to be played out. 


\section{Hypocrisy}

Silk's theme of hypocrisy bears some similarity to tolerance in that it requires two elements from the media. In the case of tolerance, the first element is for the media to permit a statement of intolerance. The second element is the media's rebuttal thereof. In the case of hypocrisy, the first element is for the media to permit religious leaders to express standards of morality. The second element is the media's exposure of the fact that the religious leaders have violated "norms of behavior that they (are presumed to) profess" (Silk, 1998, p. 91).

In spite of the fact that tolerance and hypocrisy-as topoi-have similar structural requirements, they played out very differently in coverage of the 2005 Dalai Lama visit. Regarding tolerance, reports of the visit provided no statements of intolerance. Therefore, logically, no rebuttal was necessary and the topos of tolerance was not present. Regarding hypocrisy, "norms of behavior" were introduced. Therefore the topos of hypocrisy could at least be considered. In fact, we should expect it, as Underwood (2002) whose approach to religion and media is similar to Silk's suggests that journalists enjoy looking for hypocrisy in religion, claiming that "hypocrisy is at the top of the chart when it comes to journalistic condemnation" (p. 204). Similarly, Silk (1998) himself quips that "pursuing hypocrites can be fun and games" (p. 88).

Even so, an examination of the stories here suggests that reporters did not have much fun. Very few stories had even vague hints of "hypocrisy." The closest any reporter came to charging hypocrisy (or reporting such charges made by others) in the Dalai Lama visit was an accusation that certain people failed to see the "ironies" in one of the events during his stay (September 14, "Students see peace message..."). And in this case the writer of the story funneled his description in such a way that the person who appeared most hypocritical was not a part of the Buddhist leader's retinue. This all occurred in a commentary piece, not a news article. The writer started with the broadest of accusations, that adults "dodged the ironies of the Dalai Lama's peace and compassion tour." At a narrower level in the next sentence, the commentator intimated that the "adults" of whom he spoke were best represented by "Sun Valley's super rich, high-powered business people and Gov. Dirk Kempthorne" who "fawned over" the Tibetan visitor. These words provide the first element of potential hypocrisy, a perceived attachment to the values or norms of the Dalai Lama. However, to make hypocrisy evident, the commentary writer needed to show-according to Silk- that the hypocrite violated these norms that he/she professes. Oddly, as the story was narrowed further, the "super rich, high-powered business people" were left out of the mix. No second reference was made to them, either in general terms or specific examples. Instead, the commentary writer's charge of hypocrisy was leveled only at Idaho Governor Dirk Kempthorne, who had within the previous month shown support for the war in Iraq by hosting a visit by President Bush. The suggestion was that Kempthorne demonstrated hypocrisy with his (presumably untenable) allegiance to the ideals of two radically different leaders.

Thus, the commentary writer, given free reign to express his opinions, did show that "pursuing hypocrites can be fun and games." Apparently, however, this writer found more entertainment in pursuing a single hypocrite (the Governor) than pursuing a small group ("super rich, high-powered business people") or a very large group ("adults"). The most specific charges were directed toward the first of these targets. Adults did face reproach, but nothing that suggested the level of hypocrisy the writer perceived in the Governor's actions. And super rich, high-powered business people were left out of the discussion after the initial comment about them. This was the case even though the person who was most responsible for bringing the Dalai Lama to Idaho was Kiril Sokoloff a wealthy investment broker, a Sun Valley resident, and, most notably, a practicing Buddhist. ${ }^{11}$

Interestingly, it was at the intersection of irony and wealth that another story played with the concept of hypocrisy (September 12, "Dalai Lama calls for hope..."). In this instance, however, the topos was initiated and quickly dropped. In the story that relayed the key components of the Dalai Lama's first speech, one reporter noted that the Tibetan leader called the growing gap between rich and poor one of the most disturbing recent trends. The reporter then noted, "many people commented that his remark was ironic, as the Sunday's [sic] event was held in one of the richest communities in the nation." 
This irony detected by the staff reporter is different from the irony illuminated by the commentary writer described above in significant ways. In the first instance, the commentary writer turned irony to hypocrisy and suggested that the worst hypocrite was a local politician. At one point he even contrasted the nature of such a politician with the innocence of children (who exhibit a lack of hypocrisy). "Unlike fatuous politicians," he wrote, "they [children] have raw wisdom so many adults suborn to the "realities' of the world." In the second instance of irony described above (the news story) the staff writer avoided such opportunities to pinpoint the practitioners of hypocrisy. The fact that the Dalai Lama preached a message of compassion to the super-rich could be perceived to make him a hypocrite, to make his listeners hypocrites, or perhaps both. But the writer chose to examine none of these options. Instead, she escaped the "irony" of the situation by explaining that the Dalai Lama was aware of a religious awakening among the rich, that he is writing a book about business ethics, and that he would speak directly to business leaders during this trip. These factors appear to have let everybody off the hook.

In sum, though the term "hypocrisy" was not used in any of the stories, there was one story in which discussion of the inability —or unwillingness — of a person to see the contradictory nature of some of his actions could be seen as a charge of hypocrisy. And, this was a significant theme of the story. In one other story, the opportunity also existed

to note an irony and call attention to the possibility of hypocrisy, but the writer avoided such. Oddly, within the context of the Dalai Lama's visit, the newspaper was willing to consider the possibility of hypocrisy in a non-Buddhist politician, but not in a religious leader or his most devoted followers.

\section{False Prophecy}

Whereas the topos of hypocrisy is played out when members (or better yet, leaders) of a religion fail to live up to their own standards, the next topos Silk examines can be engaged based on the standards themselves. If the basic tenets of a religion are thought by journalists to be unacceptable, the route that journalists can take to challenge the religion is the route of false prophecy.

Silk does not give a clear idea of how journalists might determine that a religious group practices false prophecy. Rather, he gives several examples of stories that were developed around this theme. He begins with $19^{\text {th }}$ century coverage of Mormonism, whose practice of plural marriage was contrary to Victorian mores. In addition, he pays some attention to the scrutiny the press gave the Rajneeshee commune in rural Oregon in the 1980s. He also devotes a large part of the end of the chapter to news coverage of David Koresh and the deadly clash his group had with federal agents in Waco, Texas in 1993. In each of these situations, the religious body or its leader was "an affront to the social order" (Silk, 1998, p. 91).

No such affront was presented in the stories studied here, and thus the topos of false prophecy was not used as a frame. This makes sense, as the topos of good works (discussed earlier) was such a common part of the Dalai Lama's message, and so widely accepted by the writers as a way to frame all aspects of his visit. Good works and false prophecy can be portrayed side by side. Silk (1998) points out that news coverage of the Latter Day Saints in the 1800s did not ignore the positive characteristics of the religion, but that it focused on the negative - specifically plural marriage — and suggested that the negative must be overcome so that the positive could be fully embraced as a fruit of the Mormon Church (p. 92). In the case of Buddhism and news coverage of one of its leader's recent visits, the positive completely overwhelmed the negative, as nothing unpleasant was written about the venerable monk.

\section{Inclusion}

The positive portrayal of Buddhism is perhaps even more evident in the next topos in Unsecular Media, the topos of inclusion. Silk argues that the Judeo-Christian origins of the theme can be seen in the New Testament letter to the Colossians, where the Apostle Paul says, "there is neither Greek nor Jew, circumcision nor uncircumcision, Barbarian,

Scythian, bond nor free." According to Silk (1998), this frame is now a means by which certain "suspect faiths" are eventually given full admission into American culture, that they are "shown to be composed of good Americans worshipping according to their own worthy lights" (p. 106). 
The word "light" is, coincidentally, a key term in one article where the topos of inclusion was incorporated in the Statesman's coverage of Buddhism. In fact, the topos was used in the premiere article of the series. On the day of the Lama's first event, the headline on the front section of the paper-in anticipation of the event-was, "Dalai Lama's visit shines a light on Idaho Buddhists" (September 11). The brief article suggested that throughout the week ideas would be presented "from a Buddhist perspective." It directed readers to four other articles inside the paper, suggesting, "here's a chance to learn a bit more of what that means as four Idahoans share their experiences with Buddhism."

And what is the nature of those experiences? In some ways, they can be easily understood by the headlines that introduced each (all on September 11). The first talked about a conversion experience ("It just clicked in my mind and heart"). The second suggested that some Americans find their transition to Buddhism is a realization of their true nature rather than a change in their way of viewing the world ("I didn't know all along I was a Buddhist"). The third explained that the religion leads to introspection ("It rooted me into facing my mind"). The final headline demonstrated that many adherents find beneficial changes resulting from their spiritual practice ("I'm not as overcome by what happens. I don't get as angry").

Within the articles themselves, the people who said these things were indeed shown to be "good Americans" (in Silk's words). Part of their goodness was indicated by the fact that they appeared to be average middle class citizens. They were teachers, artists, and retired military. Some were shown to be married and have families. In addition, for three of them, Buddhism itself was said to be a significant factor in making them better persons. One of the interviewees decided to change careers in order to move into a profession that would "help others." A second claimed that he became more patient and overcame a violent past. A third, as noted in one of the headlines, used her religion to control her anger. Much like Silk claims Judaism was shown to be worthy of inclusion by being deemed an "ethical faith" in 1950s media coverage, Buddhism here appears to be portrayed equally so. According to the inclusion topos, then, the religion is worthy to be interwoven into the fabric of mainstream American faith.

Perhaps the most blatant sign of inclusion, however, was the coverage of a visit between the Dalai Lama and representatives of other religious bodies. One of the last events of the Tibetan leader's stay in Idaho was an "interfaith meeting." As evidence of the strength of the topos, the lead sentence in the story that reviewed the meeting (September 15, "Dalai Lama asks Idaho...") was reminiscent of the verse from Colossians that Silk used to introduce his chapter. "Jew and Muslim, Catholic and Native American, Buddhist and Baha'i, Church of Jesus Christ of Latter-day Saints and Evangelical Christian-spiritual leaders from across Idaho and beyond convened Wednesday inside a heated marquis at the home of Kiril Sokoloff to chat with His Holiness the Dalai Lama." The story explained that the event began with a Native American prayer, included a dialogue where the Buddhist leader encouraged his listeners to look for what their religions share in common, and ended with a prayer by a local Rabbi. Below the story was a group of quotations from seven visitors to the event. In the first of these an evangelical pastor admitted the likable nature of the main speaker, but expressed skepticism of the Buddhist's pacifism and his faith in human nature (his belief that people are inherently good). But the skepticism ended there. A series of other observations from Muslims, Lutherans, Hindus and others all reflected a sense of solidarity with the visitor. One Islamic leader probably summed it up best, saying, "His message is our message." Certainly this is the epitome of inclusion, especially inclusion into American "civil" religion.

\section{Supernatural Belief}

Silk's next topos, supernatural belief, does not deal with the messages of various religions, per se. It is more directly related to events that are difficult to explain using the empirical methods of modern science. Simply put, such events are thought of as miracles.

The author of Unsecular Media claims that the press is just as happy to accept claims of miracles as it is to welcome new faiths into the American spiritual conglomerate. Scoffing at the popular notion that journalists are hard-bitten skeptics who report only what they can prove with their five senses, Silk 
proposes that reporters are very comfortable sharing other people's perceptions of the supernatural. In fact, he claims that the media's willingness to pass along news of the supernatural is higher than the willingness of many religious leaders themselves (Silk, 1998, p. 122). There is strong willingness to let those who believe in miracles speak, and reporters provide no personal judgment in such instances.

Even so, the theme of supernatural belief was not highly visible in the set of stories examined here. When journalists did briefly interject supernatural elements (not as main themes of stories) they reported other peoples' perspectives, as Silk suggests they commonly do. For example, in the profiles of Buddhists that occurred on the first day of coverage (September 11, "I'm not as overcome..."), one of the believers made reference to "chi." The reporter dutifully wrote, "Chi, pronounced 'key,' is an energy that akido practitioners believe permeates everything." Stated differently, the writer of the story has never seen chi, has not felt it, and does not know that it exists. But she accepts the fact that the Buddhist she is interviewing believes it to exist as do other believers of this persuasion. Similarly, in a later story about the Dalai Lama's dedication of a "prayer wheel" in a local park, the same reporter wrote, "Saying the mantra is believed to invoke the power of compassion. The spinning of the wheel then sends that blessing out into the world and to heal both physical and mental afflictions" (September 14, "The Dalai Lama blesses...") Again, the reporter simply states what is believed, not what actually occurs, as the latter cannot be proven. In noting this, we might wonder if the reporter read Silk's chapter on the topos of supernatural belief. At the end of that chapter, Silk shares a prescription from one journalist who had covered stories of miracles. "Talk to people and report what they say. Report what you see. Don't make judgments." According to Silk (1998), "It is exactly what most of them do" (p. 130).

\section{Declension}

The journalist's unwillingness to "make judgments" does not lead to neutrality in reporting. Silk consistently argues that the various topoi used to write about religion have the combined effect of lending support for a spiritual worldview. This creates a very positive stand toward religion. Continuing on this track, when Silk discusses his last topos (declension) he suggests that journalists often write stories that demonstrate religion is in decline. Of course, such stories are filled with woe.

In the case of the 2005 Dalai Lama visit, the theme was not present in the form Silk describes. In fact, the few stories that bore themes related to the strength of religious impulse all intimated or directly claimed that Buddhism is in ascent. In the first story in the series, one local adherent explained that twenty years ago he could find only one Buddhist group in the area (September 11, "Dalai Lama's visit..."). Since then, he has seen significant growth in the community. And in the last five years, "it has really blossomed." In a similar vein, Kiril Sokoloff, who arranged the Tibetan leader's visit, relayed his agreement with Arnold Toynbee's perception that the coming of Buddhism to the West might be the most important event of the twentieth century.

This is not to say that the tone in the stories was consistently positive. Silk hints that the concept of declension applies to more than just institutional church growth. It can spread to the general conditions of society. In addition, he clearly notes that the use of the topos is not always logical. Specifically, Silk (1997) states:

The news media reflect, in not always coherent ways, all the confusing religious mythology at large in society; that the old-time religion is in trouble; that the peoples' faith is strong; that the big church on the public square is the place to worship; and that the real spiritual action is on the margins. And, just as the existing religious establishments are always doomed to decline, just as the latest generation always seems worse than the one before, so there is always the hope, the promise, the necessity of a religious revival just around the corner. (p. 138)

Even though there was no reporting that suggested Buddhism is in decline, reporters occasionally veered into discussions of generational change. For the most part, these reflections pointed to hope. But, following a pattern Silk would predict, the reflections were far from coherent. For example, one reporter shared a claim by the Dalai Lama that the $20^{\text {th }}$ century was "the most violent in the world's history" (September 12 , 
"Dalai Lama calls for hope..."). In contrast to this, later in the same article the reporter shared how the Tibetan leader believed compassion "is spreading and it did throughout the $20^{\text {th }}$ century." Similarly, there was an occasional muddled combination of doom and hope in reporting about the Dalai Lama's presentation to a large group of school children. The overall message was that children have inherent innocence and our hope should rest in them. The Statesman's commentary writer even said as much in a quotation shared earlier, writing that the young have "raw wisdom." As Silk would probably point out, there is a slight contradiction here, in that almost eight thousand of these wise youths took busses to gather and listen to a septuagenarian. And, adding to the incoherence, the elderly man explained to the children in his audience that as a youth he very much enjoyed fighting other children. He went on to say that this is not his true nature. This disclaimer, and his statement that the children in the audience gave him "a sense of confidence and courage about the world," allowed the reporter to frame the story positively. Though we as a culture are not sure whether children are innocent sources of human virtue or blank slates on which we need to inscribe the wisdom of elders such as the Dalai Lama, we still have hope.

In summarizing Buddhism and declension, then, the religion itself is nowhere shown to be in jeopardy of deteriorating or fading away. And, there is much positive tone in the reporting of that fact. Even so, there appears to be some ambivalence about the state of the environment in which Buddhism finds itself. On the whole, though, these reports intimated that people such as the Dalai Lama could make the world a better place.

\section{Discussion}

There were two broad questions that I wished to address with the analysis provided above. The first key question regarded the extent to which coverage followed patterns similar to what Mark Silk delineated in Unsecular Media. The second key question asked what the overall tone of coverage was. The answers to both are very clear within the analysis above and need only slight elaboration here. However, the answers provided raise other significant issues that are very deserving of further discussion and study.

In regard to the key research question about topoi, many of the stories examined here did very clearly conform to the patterns Silk has found in his study of Western religion. Almost all of the topoi that Silk has recognized were used. Table 2 gives an overview of which topoi were utilized in which stories.

\begin{tabular}{|c|c|c|c|c|c|c|c|c|}
\hline \multicolumn{9}{|c|}{ TABLE 2} \\
\hline \multicolumn{9}{|c|}{ Use of Topoi in Dalai Lama Stories } \\
\hline Date & Headline & $\mathrm{D}$ & $\mathrm{F}$ & $\mathrm{G}$ & $\mathrm{H}$ & $\mathrm{I}$ & $\mathrm{S}$ & $\mathrm{T}$ \\
\hline 11-Sep-06 & Dalai Lama's visit shines a light... & & & $\sqrt{ }$ & & & & \\
\hline \multirow[t]{6}{*}{ 11-Sep-06 } & "It just clicked in my mind and heart." & & & $\sqrt{ }$ & & $\sqrt{ }$ & & \\
\hline & "I didn't know that all along I was a Buddhist." & & & $\sqrt{ }$ & & $\sqrt{ }$ & & \\
\hline & "It rooted me into facing my mind." & & & & & $\sqrt{ }$ & & \\
\hline & "I'm not as overcome by what happens." & & & $\sqrt{ }$ & & $\sqrt{ }$ & $\sqrt{ }$ & \\
\hline & What is Buddhism? & & & & & & & \\
\hline & Buddhism in the West. & & & & & & & \\
\hline \multirow[t]{3}{*}{ 12-Sep-06 } & Dalai Lama calls for hope, compassion. & $\sqrt{ }$ & & $\sqrt{ }$ & & & & $\sqrt{ }$ \\
\hline & "His message of peace and kindness speaks to me." & & & $\sqrt{ }$ & & & & \\
\hline & Dalai Lama reminds Americans of their rights. & & & & & & & \\
\hline \multirow[t]{2}{*}{ 13-Sep-06 } & "The century of compassion is your responsibility." & $\sqrt{ }$ & & $\sqrt{ }$ & & & & \\
\hline & His Holiness blesses a family coping with tragedy. & & & $\sqrt{ }$ & & & & \\
\hline \multirow[t]{2}{*}{ 14-Sep-06 } & The Dalai Lama blesses Idaho garden prayer wheel. & & & $\sqrt{ }$ & & & $\sqrt{ }$ & \\
\hline & Students see peace message missed by adults. & & & $\sqrt{ }$ & $\sqrt{ }$ & & & \\
\hline \multirow[t]{2}{*}{ 15-Sep-06 } & Dalai Lama asks Idaho religious.. & & & $\sqrt{ }$ & & $\sqrt{ }$ & & \\
\hline & Thoughts about the interfaith meeting... & & & & & $\sqrt{ }$ & & \\
\hline
\end{tabular}

a Topoi are abbreviated as follows: Declension, D; False prophecy, F; Good works, G; Hypocrisy, H; Inclusion, I; Supernatural belief, S; Tolerance, T. 
The reader will note that the only one that was not used at all was false prophecy. All others were used in some form, as shall be discussed presently.

Indeed, the amount of use each topos received has a clear relation to the second research question, the question of the overall positive or negative tone. Topoi that could generally be deemed positive were used readily in this coverage. Negative topoi were either not used at all or were used in interesting ways that actually increased positive portrayal of Buddhism as a religious experience. Notably, the topoi of good works and inclusion were used numerous times. Most stories could be seen to fit into one of these two frames. Topoi that could be used to point out negative aspects of a religion were either: not used (false prophecy); used in ways that incriminated others instead of incriminating Buddhists (hypocrisy, tolerance); or used in incoherent ways that made positive/negative associations difficult (declension). Finally, if supernatural belief is seen as a neutral topos because of the distance reporters take to it, we can note that it was present, but downplayed as would be expected. On the few occasions when supernatural beliefs were introduced, religious adherents were allowed to express their views about them without any judgment from reporters.

In many ways, discussion of the use of topoi makes the answer to the second key question-the question about tone of coverage-of this study obvious. The coverage was undeniably positive. Few unflattering things were said about the Dalai Lama or his religion. He was consistently presented as a very respected, wise, and thoughtful spiritual leader. His followers were also presented as spiritual people who are seeking to better themselves and the world around them.

One key finding here, then, is that the media are clearly not "anti-religious." This is supportive of the overall thrust of Silk's work, as he argues throughout his book that religion-broadly defined-is supported by the media. The best way to describe Statesman coverage is that it proclaimed Buddhism to be a good thing and that the paper provided a call to more purposefully weave Buddhism into the tapestry of American religious experience.

But this leads to another important issue. What is the nature of Buddhism, according to these stories? Or, to ask the question in other words, if these stories were the only means by which a person knew anything about Buddhism, what would the person think Buddhism is? The simple answer is that Buddhism is an amorphous religion that is not easily distinguished from many others. Elements of Silk's book might have helped us predict this, but perhaps the author does not give this possibility and its implications the attention they deserve. In his own words, he says, "Inclusion stories do tend to rub away the sharp edges of religious distinctiveness, but then, American culture as a whole has a way of doing that" (Silk, 1997, p. 139). What Silk fails to note is that the media specifically (an increasingly potent element within the abstract category he refers to as "American culture") play a very important role in this process. ${ }^{12}$ In the case of The Statesman coverage, some analysis of basic Buddhist beliefs was provided in a " $Q$ and A" section on the first day (September 11, "What is Buddhism?"). After that, very little information was provided to help understand the distinctives of the religion. If readers missed the "Q and A section," they may have had difficulty discerning what makes Buddhism different from any other religion. Compounding this difficulty was coverage of the interfaith service near the end of the Dalai Lama's visit (September 15, "Dalai Lama asks Idaho..."). The journalist who wrote about that event gave brief allusion to a Nez Perce song that was intended "to help us find our direction" and a Rabbi's prayer. No mention was made of the nature of such songs/prayers and to whom (if anyone) they were directed. In the quotations that accompanied this story, a local Hindu said, "Hare Krishnas also have the same understanding that God is one." Nowhere is there clarification of which other religions the Hindu was saying have the same understanding as his. To those with some background in world religions, this might be a bit confusing. Buddhism, after all, is not a theistic religion in the sense of recognizing a single omnipotent God. ${ }^{13}$ So discussion of such a God is not germane. And certainly there are striking theological differences about the nature of god—or gods—even between Hinduism and Christianity (many attendees were local pastors and priests).

The issue this raises is the extent to which rubbing away "the sharp edges of religious distinctiveness"- to return to Silk's original terminology_is a natural part of the inclusion of new religions within American culture. Might such erosion be avoided if those who communicate about religion were more precise in 
explaining clear historical differences that exist between religious points of view? Or (to be a bit more critical), do reporters assist in the softening of sharp edges by ignoring religious differences? Do they have a tendency to do so, even when they make full use of the topoi Silk describes? Do they have a tendency to do so because they make full use of the topoi Silk describes?

Unfortunately, Silk does not show great concern for these matters. To the contrary, he actually plays a part in blurring distinctions. To give one example, he introduced his chapter on inclusion with a verse from the New Testament, intending to suggest that the topos of inclusion is deeply embedded in the Christian faith. The specific verse is from the book of Colossians and (in Silk's text) reads as follows: "Where there is neither Greek nor Jew, circumcision nor uncircumcision, Barbarian, Scythian, bond nor free... [ellipsis in original]" Observant readers might have noticed that the author cut off the verse in an unusual place, as the verse - in the form relayed to readers-is a fragment of an idea. And, if readers pursued the matter further they might have been quite astounded. Colossians 3:11 continues and provides a qualifier that limits the "inclusiveness" Silk tries to accentuate in using it as a call for inclusion. In the King James Version (a very well respected translation among Protestant denominations), the verse says "Where there is neither Greek nor Jew, circumcision nor uncircumcision, Barbarian, Scythian, bond nor free: but Christ is all, and in all." Here, then, it is Mark Silk who helps to wear away the clear sharp edges of Christianity that separate it from all other religions. Whereas orthodoxy teaches that Jesus Christ is the essence of the Christian faith and only those who accept his sacrifice are part of that faith, Silk uses Christian scripture in a way that suggests otherwise.

Given this and many other observations above, we might begin to wonder if the topos of inclusion, which Silk sees as an underpinning ethos of "Western religion," is not as much a part of Judaism and Christianity as he claims it to be. And, perhaps the other six topoi are equally suspect. These are, perhaps, issues worthy of attention from scholars in religion more than scholars in media. They are worthy of attention nonetheless. Silk has made a bold claim that seven concepts are bedrock principles of Judaism and Christianity. One important project involved in further discussing his work is the task of unpacking each topos and making a more labored argument for whether it is or is not a product of Judeo-Christian religious thought.

Looked at from a different direction, there is another important issue here. Even if we take for granted that Silk's seven topoi are in some way reflective of the Western religious tradition, is it possible that the topoi are so broadly defined that they are key elements of many (or perhaps all) religious faiths? This is another area worthy of further research. Would analysis of other news coverage of Buddhism exhibit the same use of topoi and the same positive tone? Would analysis of news coverage of Hinduism show the same results? And, there are other possible avenues for trying to address these issues. In the same way that research is needed to determine if Silk's topoi are truly Judeo-Christian in origin, further research could be conducted to determine the extent to which members of non-Western faiths would claim allegiance to the seven key topoi. Would most Buddhist's see "good works" to be "deeply ingrained," or, a "fundamental part," of their religion (Silk, 1997, p. 54)? Obviously, this and the other questions above cannot be answered at this time. But we do know from the material above that Silk's topoi are not Judeo-Christian in any clearly essentialusing the term in its philosophical sense-form. That is, they are not a means of clearly distinguishing Christianity from other religions.

All of this addresses the question of what Silk's topoi are not. We have yet to face directly the question of what Silk's topoi might be. Some help in answering that question may be provided by Underwood, who shares certain preconceptions with Silk, but has a different emphasis. Agreeing with Silk that there is an undercurrent in the media that precludes claims of "anti-religious bias," he also recognizes that the undercurrent shows attachment only to certain moral aspects of Western religion. The undercurrent actually shows a rather low affinity for the bedrock theology of Judaism and Christianity. In his own words, Underwood (2002) writes:

Finally, our analysis suggests a reexamination of the claim that journalists are 'hostile' toward religion because there is much evidence that they have great sympathy for religious values. But, we must be careful not to mistake this sympathy for an overt embrace of religion in their work or explicit support for 
the expression of religious viewpoints in their professional activities. The high levels of support for the "ambivalent" maxims (the ones where journalistic figures showed sympathy for core Judeo-Christian calls for justice and selfsacrifice but not necessarily orthodox theology) indicate that many journalists are uncomfortable with evangelizing or creedal confessions. (p. 147).

Underwood's preciseness explains much of what has been observed above. The news coverage of the Dalai Lama visit showed a high level of respect for Buddhism when broadly defined, but gave scant attention to its spiritual dimensions. This does not contradict what Wall found in her study of news coverage of a young Seattle Lama. She interpreted the stories she studied to denigrate Buddhist beliefs such as reincarnation (Wall, 1999, p. 15). Here, those beliefs were ignored. This observation also fits neatly with earlier discussion of the way the media blur the differences between different faiths. Either action (denigrating theological distinctions, or ignoring them) could lead to a devaluation of "sharp edges of religious distinction."

What element is elevated in importance in the place of these religious details? As already noted by analyzing news content through the lens of Silk's topoi-and as forewarned in the Underwood quotation just shared-the most important thing is "good works." Underwood equates good works with "calls for justice and self-sacrifice." In the news stories studied here these received the attention that deep questions such as the nature of the human spirit did not. Presumably they were of utmost importance to the reporters who wrote about the Dalai Lama.

Admittedly, these (good works, justice, self-sacrifice) are crucial aspects of the Western religious tradition. So Silk is correct to suggest that allegiance to these ideas is supportive of Western religion. But by now the reader should have noted that they only support part of Western religion. Underwood (2002) offers continued insight by recognizing a juncture that was critical in the history of American journalism, but also a reflection of a divide that has been common in Christianity (the most prominent Western religion).

The muckrakers raised an important question that continued to divide Christians: was Jesus a figure of spiritual salvation or was he an activist seeking a just society? An important strand of modern journalism in America has followed the muckraker tradition of embracing Christian ethics and social ideals but spurning much of the rest of Christian theology. (p. 84)

In the case of Christianity, this means that reporters adopted Jesus' teachings about taking care of the poor, but ignored what he said about taking care of the soul. The same appears to take place with respect to news coverage of Buddhism. Reporters are happy to report that the Dalai Lama wants us to have compassion, but a bit reluctant to discuss the fact that he claims to be the reincarnation of an earlier Buddhist teacher.

Another way to say this is to say that the press is most interested in what religion has to say about the worldly and the temporal. In regard to the worldly aspect, all of the focus is on the grounded dimensions of religion, for example, the portion that relates to how each of us treats his/her fellow humans. That is to say, the media are very "mundane." Tracing the word to its Latin roots, this signifies that the media focus on worldly matters. Left out of press coverage and much of Silk's discussion are the truly transcendent aspects of faith. This also relates to the aspect of temporality. The Dalai Lama spoke of the ravages of war, the tragedy of Katrina, the widening gap between rich and poor, all problems that face us in our immediate time-bound existence. With these thoughts in mind, Silk's view of the media as "unsecular" is—quite ironically — well off the mark. After all, if as we did with the word "mundane" we take the word "secular" back to its Latin roots, we realize that the media have much to do with "this world." Basically, something that is "secular" relates to the current period or age.$^{14}$ In this light, issues of "morality" (how we treat each other today) are extremely secular issues. What is not secular is discussion of questions such as whether there is a God (especially if that God is somehow outside of our notions of time and space) and what our relationship to that God might be. As we have seen, Silk's putatively unsecular media devote little attention to these matters. They are quite secular, even if they sometimes like to engage in moral speculation. 
And certainly this is the bone of contention that a large part of the American population has with the mass media. Though they might not state it with the preciseness that Underwood did above, they recognize that American journalists face choices in how to incorporate faith into media practice. And these Americans disagree with the muckrakers' choice in the dichotomy of Christian moral or soteriological orientation. Thus, where Silk hints that religious folk would recognize that the media have a "proreligious posture" if they only looked more closely, the argument here is that no close inspection will bridge this gap. Basically, there is a fundamental conflict between the beliefs of reporters and a part of their audience. The one author who seems to recognize this is McCloud (2004), who stated it succinctly.

Whereas Silk argues that the news media 'approach religion with values and presuppositions that the American public widely shares,' I stress that there are actually multiple, sometimes overlapping American publics that hold a variety of complex, divergent, and often contradictory views. (p. 11-12).

From this point of view, we can see that a large part of the journalistic community could have a preference for one view of religion that much of their readership does not share. In the West, this plays out in an historical choice between Christian morality and Christian theology. ${ }^{15}$ The distinction might not be as sharp in religions such as Buddhism, but still exists.

In conclusion, all of the above suggests that Silk is correct when he claims that reporters are highly respectful toward religion. But evidence presented here suggests that the type of religion that reporters respect is so amorphous, so ill-defined that it could include just about any theological or a-theological persuasion. What appears to be most important in matters of religion is that the devotees covered adhere to certain moral precepts to which the journalistic community has also claimed allegiance. Given all of this, Silk's thesis can probably best be summed up in his own words early in his book. There he states that journalists write about religion while using "ideas of what religion is and is not, of what it ought and ought not to be-with topoi-that derive, to varying degrees, from religious sources" (Silk, 1998, p. 50). The findings of this study suggest that his abstract theory gives us plenty to think about, but that the words "to varying degrees" are where the details lie as to whether American journalism is supportive of America's dominant historical religious traditions. Quite ironically, a common "Western" expression states that it is in the details that the devil lies also.

\section{References}

James Beckford, J. (1996). Mark Silk: Unsecular media: Making news of religion in America. Review of Religious Research, 38, 89-90.

Buddenbaum, J. (1986). Religion news coverage in three major newspapers. Journalism Quarterly, 63, 597-613.

Cox, H. (1978). Deep structures in the study of new religions. In J. Needleman and G. Baker (Eds.), Understanding New Religions (pp. 122-144). New York: Seabury Press.

Kornfeld, A. B. E., Reiss, V. (2006, August 14). Buddhism becomes hip marketing tool. Newsweek, 184,

McCloud, S. (2004). Making the American religious fringe: Exotics, subversives, and journalists, 19551993. Chapel Hill, North Carolina: University of North Carolina Press.

Moore, R. C. (2005). Spirituality that sells: Religious imagery in magazine advertising. Advertising and Society Review, 6:1. Retrieved, May 22, 2007, from

http://muse.jhu.edu/journals/asr/v006/6.1moore.html.

Prothero, S. (1997, May 24). Buddha chic. Salon. Retrieved May 22, 2007, from http://archive.salon.com/may97/news/news970524.html. 
Shofield Clark, L. (2002). The 'Protestantization' of research into media, religion, and culture. In S.M. Hoover and L. Schofield Clark (Eds.), Practicing religion in the age of the media: Explorations in media, religion, and culture (pp. 1-21). New York: Columbia University Press.

Silk, M. (1997). Journalists with attitude: A response to Richardson and Van Driel. Review of Religious Research, 39, 138-139.

Silk, M. (1998). Unsecular media: Making news of religion in America. Urbana, Illinois: University of Illinois Press.

Stout, D. A. (1997). Unsecular media: Making news of religion in America. Journal for the Scientific Study of Religion, 36, 126-129.

Stout, D. A, \& Buddenbaum, J. A. (2002). Foundations for the study of media and religion. Journal of Media and Religion, 1-13.

van Driel, B. \& Richardson, J. T. (1988). Print media coverage of new religious movements: A longitudinal study. Journal of Communication, 38, 37-61.

Underwood, D. (2002). From Yahweh to Yahoo!: The religious roots of the secular press. Urbana, Illinois: University of Illinois Press.

Wall, M. (1999). More Barney than Buddhist: How the media framed the story of the little lama. Paper presented at the annual meeting of the AEJMC, New Orleans, LA..

${ }^{1}$ Following the pattern of Mark Silk, I have chosen to use the terms "Eastern" and "Western" religion. Admittedly, such a dichotomy is problematic, but for purposes of the ensuing analysis it simplifies writing.

${ }^{2}$ In the index to the book, there is only one reference to Buddhism (which directs the reader to discussion of a poll done by one newspaper).

${ }^{3}$ Silk gives these people (and some of the studies they use to support their opinion) full attention in the third chapter of Unsecular Media.

${ }^{4} \mathrm{I}$ ask this on the basis that Christianity, Islam and Mormonism are offshoots of Judaism.

${ }^{5}$ A quick search in Google Scholar provides 58 entries, many of which are academic sources that have cited the book.

${ }^{6}$ Though little has been written about Buddhism in the news, there are areas where the cultural presence of the religion has been duly noted. Those who pay attention to marketing and advertising have noticed trends in acceptance of "fringe" religion, especially Buddhism. Both popular and academic writers have drawn attention to this. For example, in the late 1990s Stephen Prothero (1997) made note of the fact that advertisers used a "chic" rendition of Buddhism to sell products. A 2006 Newsweek article demonstrated even greater cultural acceptance. One entrepreneur cited in the article made reference to "profiting off of Buddha's hip, peaceful image" (Kornfeld and Reiss, 2006). A recent academic investigation into the use of religion to sell products revealed that the most common religious image used in advertising was a person meditating in the lotus position (Moore, 2005). Though each of these authors gives some suggestion that there are negative aspects of this usage (e.g., that it occurs because advertisers think of Buddhism as something exotic and nobody will be offended by the use of an exotic religion), the positive cannot be denied. As Prothero puts it, American's "have gone gaga over Buddhism."

${ }^{7}$ On page 317, Underwood shares information from a LexisNexis analysis of newspaper coverage of religion. Buddhism fared well in regards to the use of positive terms (such as "harmony") while having 
very few negative terms associated with it. Underwood admits that the study only provides a start to answering questions about the overall portrayal of the religion.

${ }^{8}$ In the two year period of 2005 and 2006, the paper went through two ownership changes, from Gannett, to Knight Ridder, and more recently from Knight Ridder to McClatchy.

${ }^{9}$ Some "sidebars" in this series were easy to count as separate stories, as they were written in news story form. Some included only questions and answers, and some included a series of quotes. Give this variety, the exact number of "stories" is difficult to quantify.

${ }^{10}$ In the sidebar that included quotations from clergy who attended the interfaith gathering, one Christian Pastor commented that he found the Dalai Lama "likeable" but thought his view of evil was "simplistic." This single negative comment was as close to an attack as I could find.

${ }^{11}$ Sun Valley is a resort community that is home to a number of wealthy business people as well as Hollywood celebrities.

${ }^{12}$ Admittedly, some of this may be a factor of the brevity of Silk's work. He occasionally brushes by these issues, but does not give them the attention they deserve. For example, in the last pages of the text, he asks whether "focusing on good works gives short shrift to what else religion can do in the world" (p. 149).

${ }^{13}$ There is some variation between the various traditions of Buddhism (e.g. Theravada and Mahayana). Though many Buddhists recognize supernatural beings, few would adhere to the notion of a creator God that is an important part of Judaism and Christianity.

${ }^{14}$ Students of romance languages might notice the word "secular" has similarity to the Spanish word "siglo" and the French word "siècle." The usage of these words in other languages gives some indications of the original meaning of "secular."

${ }^{15}$ The actual extent to which the whole of Christian morality is adopted by journalists is open for debate. Again, many Christians might feel that there is a wide chasm between their moral views and those of journalists if we take the whole range of moral issues into account. 